Lily L. Wu • Paul N. Hopkins • Yuanpei Xin

Susan H. Stephenson - Roger R. Williams • Yukiko Nobe

Mitsuko Kajita - Toshiaki Nakajima • Mitsuru Emi

\title{
Co-segregation of elevated LDL with a novel mutation (D92K) of the LDL receptor in a kindred with multiple lipoprotein abnormalities
}

\begin{abstract}
Factors predisposing to the phenotypic features of familial combined hyperlipidemia have not been clearly defined. In the course of investigating familial coronary artery disease in Utah, we identified a three-generation family in which multiple members were affected with type IIa hyperlipoproteinemia (HLP IIa), type IIb hyperlipoproteinemia (HLP IIb), or type IV hyperlipoproteinemia (HLP IV). Because several family members had relatively severe low-density lipoprotein (LDL) cholesterol elevation, in order to dissect the possible contribution to the plasma lipoprotein abnormalities in this pedigree, we identified a novel point mutation in the low-density lipoprotein receptor $(L D L R)$ gene, a G-to-A transition at nucleotide position 337 in exon 4 . This change substituted lysine for glutamic acid at codon 92 (D92K) of the LDL receptor. By means of mutant allele-specific amplification we determined that the mutation co-segregated with elevated cholesterol and LDL cholesterol in the plasma of family members with HLP IIa and HLP IIb, but not with the elevated plasma triglycerides seen in HLP IIb and HLP IV patients. Thus, in families with apparent familial combined hyperlipidemia, a defective $L D L R$ allele and other genetic or environmental factors that elevate plasma triglycerides may account for the multiple lipid phenotypes observed in this kindred.
\end{abstract}

Key words Hyperlipoproteinemia · Lipoproteins · LDL receptor $\cdot$ Familial combined hyperlipidemia

L.L. Wu · P.N. Hopkins · Y. Xin · S.H. Stephenson · R.R. Williams M. Emi

Cardiovascular Genetics Research Clinic, University of Utah Medical School, Salt Lake City, USA

Y. Nobe $\cdot$ M. Kajita $\cdot$ T. Nakajima $\cdot$ M. Emi $(\triangle)$

Department of Molecular Biology, Institute of Gerontology, Nippon Medical School, 1-396 Kosugi-cho, Nakahara-ku, Kawasaki-shi,

Kanagawa 211-8533, Japan

Tel. +81-44-733-5230; Fax +81-44-733-5192

e-mail:memi@nms.ac.jp

\section{Introduction}

Lipid and lipoprotein concentrations in plasma reflect, in part, the influence of multiple genetic loci (Zannis and Breslow 1985; Breslow 1987), in which defects are known to account for some types of hyperlipoproteinemia (HLP) that affect multiple members of certain families. However, the genetic mechanisms responsible for most types of familial dyslipoproteinemia appear to be complex, not monogenic. For instance, one of the most common forms of hyperlipidemia is familial combined hyperlipidemia (Goldstein et al. 1973). The features of familial combined hyperlipidemia include moderate elevation of plasma cholesterol, or triglycerides, or both, within individuals of an affected kindred. Familial combined hyperlipidemia should be suspected in subjects with moderate hypertriglyceridemia and/or moderate hypercholesterolemia (lipoprotein types IIa, IIb, or IV), especially in the setting of a family history of premature coronary heart disease. The diagnosis is a clinical one; it requires demonstration of the clinical phenotype in the affected individuals and family members (Mahley et al. 1998). In spite of the apparent strong predisposition to coronary artery diseases that this condition confers, whether the multiple lipoprotein patterns observed in such kindreds result from the inheritance of a single autosomal dominant allele or from multiple, distinct familial conditions cannot be clearly resolved in the absence of specific genetic markers. Yet in some families in which affected members show lipoprotein lipase (LPL) deficiency, relatives of a homozygous proband have been described with type I, type IIa, type IIb, type IV, or type V HLP (Berger and Bonnici 1977; Gagne et al. 1977; Wilson et al. 1983). These observations have led to the suggestion that heterozygosity for a mutant $L P L$ gene may be a predisposing component for the expression of familial combined hyperlipidemia (Wilson et al. 1983; Babirak et al. 1989).

We ascertained a three-generation pedigree in Utah, designated K450, in which 15 members were affected with hyperlipoproteinemia but exhibited various lipoprotein profiles. Lipoprotein analyses identified 9 individuals with 
type IIa hyperlipoproteinemia (HLP IIa; LDL cholesterol, $>90$ th percentile; normal plasma triglycerides), 3 with type IIb hyperlipoproteinemia (HLP IIb; both LDL cholesterol and plasma triglycerides, $>90$ th percentile), and 3 with type IV hyperlipoproteinemia (HLP IV; plasma triglycerides, $>90$ th percentile; normal LDL cholesterol). This pedigree therefore provided an opportunity to begin dissecting a disease by analyzing genetic variations at a candidate gene involved in lipoprotein metabolism, the LDL receptor (Goldstein et al. 1995).

\section{Materials and methods}

\section{Patients and lipoprotein measurement}

Participants in this study were members of a single pedigree that were seen at the Cardiovascular Genetics Research Clinic of the University of Utah. After they had fasted for 12-16h, untreated blood samples were collected from all 24 participating family members. Lipid and lipoprotein concentrations were measured by procedures described previously (Wu et al. 1989). In brief, plasma cholesterol and triglyceride concentrations were assayed enzymatically, concentrations of high-density lipoprotein cholesterol (HDL-c) were determined by $\mathrm{MgCl}_{2}$-dextran precipitation, and plasma lipoproteins were centrifuged in a Beckman TL100 tabletop ultracentrifuge (Beckman, CA, USA) for $4 \mathrm{~h}$ at $60,000 \mathrm{rpm}$ at room temperature, and thereafter separated into top (very low-density lipoprotein; VLDL) and bottom (LDL plus HDL) fractions by tube slicing. This method was important in the differential diagnosis of HLP III from other types of HLPs.

Single-strand conformational polymorphism (SSCP) analysis and DNA sequencing

Initial polymerase chain reactions (PCRs) were carried out using $20 \mathrm{ng}$ of genomic DNA extracted from lymphocytes, each in a $10-\mu l$ aliquot of solution containing $10 \mathrm{mM}$ Tris$\mathrm{HCl}(\mathrm{pH} 8.4), 50 \mathrm{mM} \mathrm{KCl}, 1.5 \mathrm{mM} \mathrm{MgCl}, 0.01 \%$ gelatin, $200 \mu \mathrm{M}$ of each dNTP, $2 \mu \mathrm{Ci}$ of [alpha $\left.{ }^{32} \mathrm{P}\right]$-dCTP $(3,000 \mathrm{Ci} /$ $\mathrm{mmol}, 10 \mathrm{mCi} / \mathrm{ml}), 2.5 \mathrm{pmol}$ of each primer, and 0.25 units of Taq polymerase (Tsukamoto et al. 1998). PCR primers for amplification of each exon of the $L D L R$ gene and all its exon-intron boundaries were described by Leitersdorf et al. (1990) or by Leren et al. (1993). Each of 35 PCR cycles consisted of $30 \mathrm{~s}$ at $94^{\circ} \mathrm{C}, 30 \mathrm{~s}$ at $71^{\circ} \mathrm{C}$, and $30 \mathrm{~s}$ at $72^{\circ} \mathrm{C}$. Reaction mixtures were diluted with $50 \mu \mathrm{l}$ of $95 \%$ formamide dye and $20 \mathrm{mM}$ ethylenediamine tetraacetic acid (EDTA), incubated at $85^{\circ} \mathrm{C}$ for $5 \mathrm{~min}$, and applied $(2 \mu \mathrm{l} /$ lane) to $6 \%$ polyacrylamide gels containing $0.5 \times \mathrm{TBE}$ (90 mM Tris-borate/2 mM EDTA) and 5\% glycerol. Electrophoresis was performed both at room temperature and at $4^{\circ} \mathrm{C}$ (Hirayama et al. 1998). The gels were dried and autoradiographed with intensifying screens. When a variant band was revealed by SSCP analysis, the corresponding
DNA fragment was sequenced directly on both strands to identify the nature of the mutation. Each result was confirmed by two independent experiments.

\section{Mutant allele-specific amplification (MASA)}

Genomic DNA was extracted from lymphocytes of 17 family members. PCR amplifications were carried out using $20 \mathrm{ng}$ of genomic DNA, $10 \mathrm{mM}$ of Tris- $\mathrm{HCl}(\mathrm{pH} 8.4), 50 \mathrm{mM}$ of $\mathrm{KCl}, 1.5 \mathrm{mM}$ of $\mathrm{MgCl}_{2}, 0.01 \%$ gelatin, $200 \mu \mathrm{M}$ of each dNTP, $2.5 \mathrm{pmol}$ each of mismatched primer (5'TCGGCCATCCATCCCTGCAG-3') on one side and normal primer (anti-sense: 5'-CTGCGGCCACTCATCCGAGC- $3^{\prime}$ ) on the other side, and 0.25 units of Taq polymerase, in a volume of $10 \mu \mathrm{l}$ (Hopkins et al. 1999). Cycle conditions were $94^{\circ} \mathrm{C}$ for $3.5 \mathrm{~min}$, then 30 cycles of $94^{\circ} \mathrm{C}$ for $30 \mathrm{~s}, 71^{\circ} \mathrm{C}$ for $30 \mathrm{~s}$, and $72^{\circ} \mathrm{C}$ for $30 \mathrm{~s}$, with a final extension step of $3.5 \mathrm{~min}$ at $72^{\circ} \mathrm{C}$, in a Gene Amp PCR 9600 System (PE Biosystems, Foster City, CA, USA). PCR products were electrophoresed in 3\% agarose gels and visualized by ethidium-bromide staining.

\section{Statistical analysis}

Plasma lipoprotein levels in individuals who possessed the mutant $L D L R$ allele and in individuals who did not were compared using non-parametric (Student-Newman-Keuls) analysis. Differences in means were considered statistically significant at $P$ values $<0.05$.

\section{Results}

The pedigree structure of K450, and the ages and untreated lipoprotein profiles of all 24 members examined, are shown in Fig. 1. Nine members of the family exhibited the lipoprotein phenotype of HLP IIa, three that of HLP IIb, and 3, that of HLP IV, suggesting a diagnosis of familial combined hyperlipidemia. The proband was a 43 -year-old Caucasian woman (individual II-3; Fig. 1) who was diagnosed with HLP IIb. The elevated LDL cholesterol (LDL-c) levels common in her family appeared to follow a Mendeliandominant mode of inheritance when treated as a single trait, which led us to suspect segregation of a defective $L D L$ receptor allele in this family.

When we screened the proband's genomic DNA for mutation of the $L D L R$ gene, we identified an aberrant SSCP pattern in the PCR product of exon 4 (Fig. 2a). Direct sequencing on both strands revealed heterozygosity for a Gto-A transition at nucleotide position 337 of the $L D L R$ cDNA. This transition would substitute lysine for glutamic acid at codon 92 (D92K; Fig. 2b). D92K was the only sequence variation detected in the entire coding region or splice-site consensus sequences.

Diagnosis of the D92K mutation was carried out by mutant allele-specific ampification (MASA) in all 17 members of the proband's family from whom genomic DNA was 


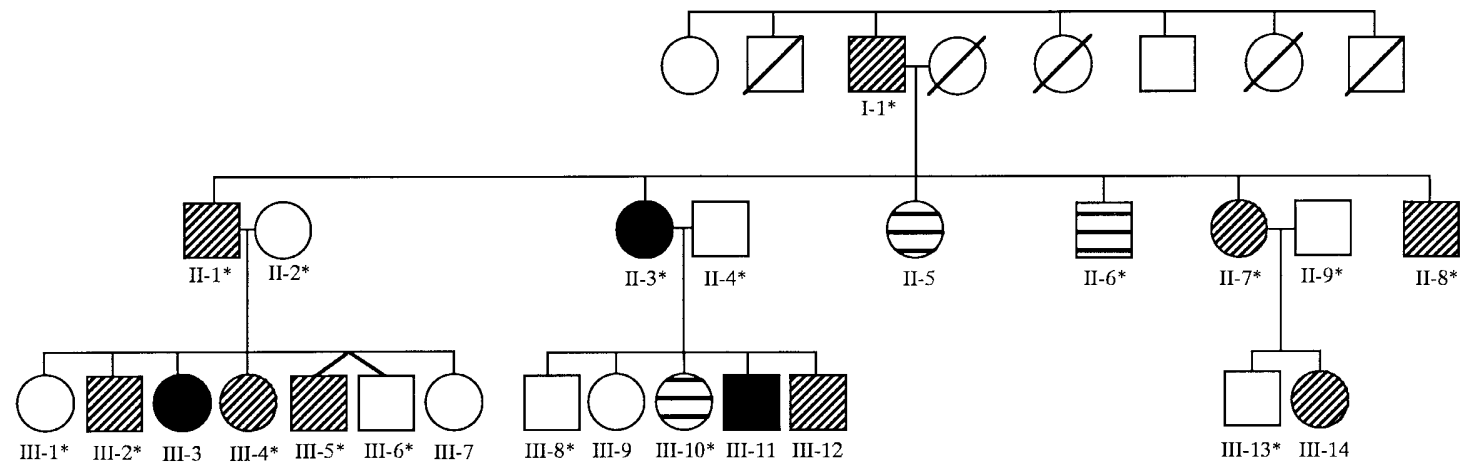

\begin{tabular}{lccccccccccccccccccccccccccc}
\hline ID & I-1 & II-1 & II-2 & II-3 & II-4 & II-5 & II-6 & II-7 & II-8 & II-9 & III-1 & III-2 & III-3 & III-4 & III-5 & III-6 III-7 & III-8 & III-9 III-10 III-11 III-12 III-13 III-14 \\
age & 64 & 43 & 44 & 43 & 46 & 39 & 35 & 29 & 24 & 50 & 21 & 19 & 16 & 13 & 9 & 9 & 7 & 22 & 18 & 7 & 12 & 10 & 5 & 4 \\
T.Chol & 302 & 443 & 222 & 294 & 223 & 226 & 200 & 259 & 292 & 131 & 200 & 268 & 298 & 324 & 326 & 252 & 228 & 222 & 184 & 213 & 248 & 223 & 166 & 204 \\
TG & 106 & 278 & 94 & 370 & 164 & 240 & 316 & 160 & 193 & 59 & 103 & 149 & 240 & 95 & 98 & 103 & - & 107 & 119 & 172 & 183 & 109 & 66 & 55 \\
HDLc & 47 & 40 & 50 & 45 & 48 & 34 & 36 & 37 & 40 & 45 & 57 & 48 & 50 & 54 & 58 & 64 & - & 44 & 44 & 45 & 41 & 42 & 56 & 48 \\
LDLc & 237 & 286 & 159 & 168 & 153 & 143 & 101 & 195 & 204 & 74 & 127 & 185 & 185 & 257 & 232 & 157 & - & 139 & 121 & 129 & 164 & 170 & 101 & 148 \\
\hline
\end{tabular}

Fig. 1. Pedigree and lipoprotein analysis of the K450 kindred. Square symbols, Males; circles, females. Deceased members are indicated by single lines struck through the symbols. Asterisks denote the 17 family members from whom DNA samples were available for genotyping. Diagonally hatched symbols, individuals with hyperlipoproteinemia
(HLP) IIa; black symbols, individuals with HLP IIb; symbols with horizontal lines, individuals with HLP IV. T. Chol, Total cholesterol; $T G$, plasma triglyceride; $H D L c$, high-density lipoprotein cholesterol; $L D L c$, low-density lipoprotein cholesterol a

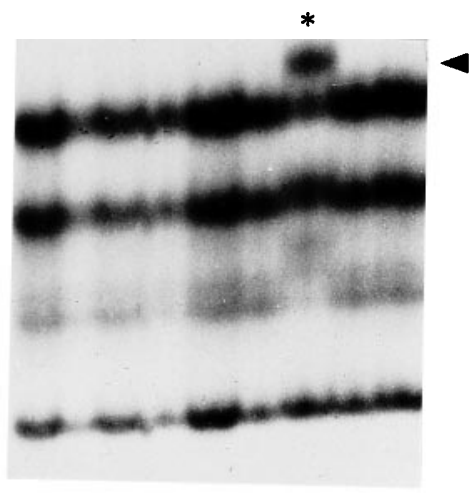

\section{b} $3^{\prime}$ Normal

Proband

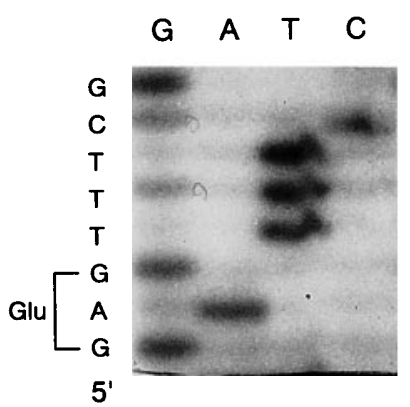

$3^{\prime}$
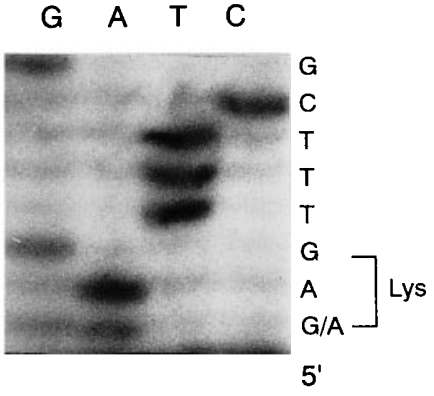

Fig. 2. a Single-strand conformational polymorphism (SSCP) analysis of exon 4 of the LDL receptor gene in the proband. Arrow head indicates the aberrant SSCP band observed in her DNA. b Nucleotide sequencing pattern and deduced amino acid sequences of the D92K mutant and a normal allele. Asterisk indicates proband DNA

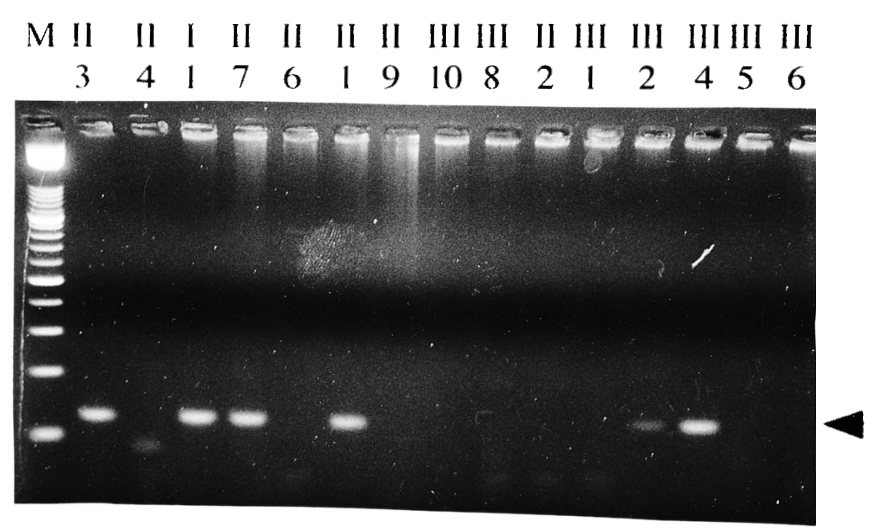

Fig. 3. Mutant allele-specific amplification (MASA) analysis for the D92K mutation. Positive bands in DNA specimens from affected individuals were visualized by ethidium-bromide staining of polymerase chain reaction (PCR) products and electrophoresed on 3\% Nusieve (Takara, Tokyo) agarose gels. Lane $m$, size marker; Roman and arabic numerals on other lanes correspond to family members shown in pedigree in Fig. 1

available. Representative results are shown in Fig. 3. The MASA test detected mutant alleles of LDLR in 8 individuals. These individuals contained at least one mutant allele. The other 9 people were excluded from carrier status (Table 1$)$. The mean $( \pm \mathrm{SD})$ values for total cholesterol (TC), plasma triglyceride, LDL cholesterol, and HDL cholesterol are illustrated by histograms in Fig. 4. In mutation carriers, total cholesterol and LDL-c levels were significantly increased ( $P<0.003$ for TC; $P<0.0001$ for LDL-c) compared with levels in non-carriers, whether or not the 
T.Chol

TG

LDL-c

HDL-c
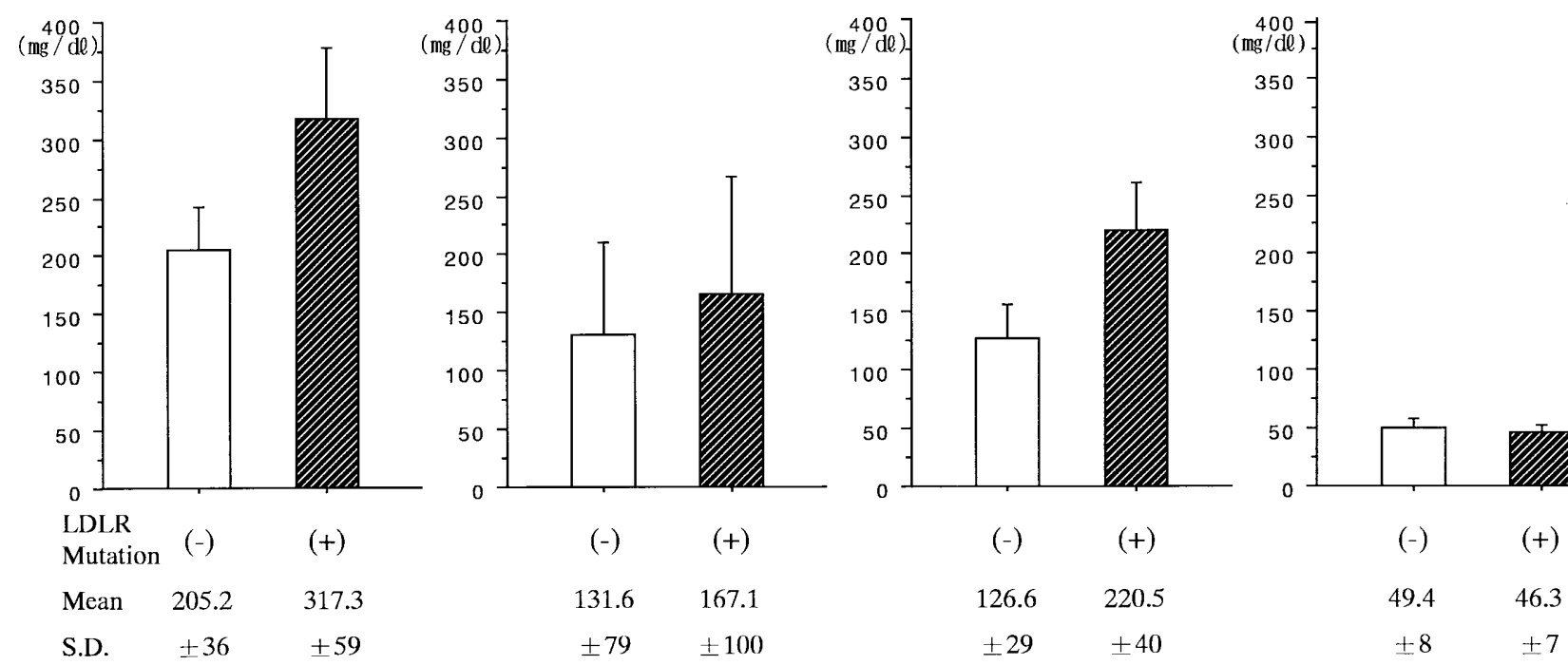

Fig. 4. Means and standard deviations (S.D.) of total cholesterol (T. Chol), triglyceride (TG), LDL cholesterol ( $L D L-c)$, and HDL cholesterol (HDL-c) among non-carriers (open bars) and carriers (hatched bars) of the LDLR D92K mutation

Table 1. Lipoprotein profiles of $\mathrm{D} 92 \mathrm{~K}$ carriers and non-carriers

Mutation carriers

\begin{tabular}{lllllll}
\hline No. & Age (years) & TC & TG & HDL & LDL & VLDL \\
\hline I-1 & 64 & 302 & 106 & 47 & 237 & 15 \\
II-1 & 43 & 443 & 278 & 40 & 286 & 118 \\
II-3 & 43 & 294 & 370 & 45 & 168 & 73 \\
II-7 & 29 & 259 & 160 & 37 & 195 & 35 \\
II-8 & 24 & 292 & 193 & 40 & 204 & 40 \\
III-2 & 19 & 268 & 149 & 48 & 185 & 42 \\
III-4 & 13 & 324 & 95 & 54 & 257 & 30 \\
III-5 & 9 & 326 & 98 & 58 & 232 & 36 \\
Average & 30 & 313 & 181 & 46 & 220 & 49 \\
\hline
\end{tabular}

Non-carriers

\begin{tabular}{lllllll}
\hline No. & Age (years) & TC & TG & HDL & LDL & VLDL \\
\hline II-2 & 44 & 222 & 94 & 50 & 159 & 23 \\
II-4 & 46 & 223 & 164 & 48 & 74 & 28 \\
II-6 & 35 & 200 & 316 & 36 & 101 & 79 \\
II-9 & 50 & 131 & 59 & 45 & 127 & 8 \\
III-1 & 21 & 200 & 103 & 57 & 127 & 22 \\
III-6 & 9 & 252 & 103 & 64 & 157 & 27 \\
III-8 & 22 & 222 & 107 & 44 & 139 & 28 \\
III-10 & 7 & 213 & 172 & 45 & 129 & 29 \\
III-13 & 5 & 116 & 66 & 56 & 101 & 11 \\
Average & 27 & 203 & 132 & 49 & 127 & 28 \\
\hline
\end{tabular}

No., Corresponds to family members shown in the pedigree in Fig. 1 TC, Total cholesterol; TG, plasma triglyceride; HDL, high-density lipoprotein cholesterol; LDL, low-density lipoprotein cholesterol; VLDL, very low-density lipoprotein cholesterol

carriers had presented with either HLP IIa or HLP IIb. However, triglyceride (TG) and HDL-c levels did not differ significantly between carriers and non-carriers of the $L D L R$ mutation ( $P=0.265$ for TG; $P=0.400$ for HDL-c).

Among the 17 genotyped members, all HLP IIa and HLP IIb patients carried the D92K mutation, but neither of the two HLP IV patients did. These data were evidence that elevated levels of total and LDL cholesterol reflected inheritance of the D92K mutation of the $L D L R$ gene in $\mathrm{K} 450$, while plasma triglyceride and HDL cholesterol levels did not.

\section{Discussion}

In this study we examined a kindred with multiple lipoprotein abnormalities. As this family was notable for lack of consanguinity and lack of confounding valuables such as smoking or abuse of alcohol, it provided a unique test population for clarifying genetic components associated with apparent familial combined hyperlipidemia. The phenotype associated with inheritance of the $\mathrm{D} 92 \mathrm{~K}$ mutation of $L D L R$ in this kindred was elevated plasma levels of total cholesterol and LDL-cholesterol; this phenotype alone was transmitted in an autosomal dominant fashion.

Two hypotheses for the genetic mechanism of familial combined hyperlipidemia, either the "single-gene hypothesis" or the "multiple-gene hypothesis" were tested in the present study. Through genetic analysis, we showed that one of the prominent phenotypes, elevated LDL cholesterol, segregated with genetic defect at one locus $(L D L R)$, but the other characteristic phenotype, elevated plasma triglycerides, did not co-segregate with that locus. This explains the presence of members with a normal $L D L R$ allele having HLP IV. Thus, elevated plasma triglycerides was most likely to be explained by an unknown factor, genetic or environmental. These data are consistent with the "multiple-gene hypothesis" for familial combined hyperlipidemia etiology, at least in this pedigree. 
We previously reported four hyperlipidemic extended pedigrees with a complex lipoprotein phenotype, and showed that elevated LDL cholesterol concentrations in that family also were due to a defective $L D L R$ gene. Furthermore, we showed that HLP III occurred among individuals who inherited a defective $L D L R$ allele and also a defective allele of the apolipoprotein E gene (apoE2). The latter allele had a striking effect on remnant accumulation, expressed as the VLDL cholesterol-to-plasma triglyceride ratio only among individuals who also carried defective LDLR alleles (Emi et al. 1991; Hopkins et al. 1991). That study provided an early example of genetic interactions resulting in the manifestation of a separate lipoprotein abnormality.

Attention has been focused recently on the influence of lipoprotein lipase (LPL) and cholesteryl ester transfer protein (CETP) on plasma HDL-cholesterol levels in carriers of mutant $L D L R$ alleles, when heterozygotes for defective LDL receptors also carry mutations of either LPL or CETP (double heterozygotes). Pimstone et al. (1995) noted that mutations that reduced LPL activity were associated with lower HDL-cholesterol levels in familial hypercholesterolemia (FH)-heterozygotes, and suggested a positive relationship. On the other hand, mutant alleles of CETP were associated with increased HDL-cholesterol levels in Japanese patients with heterozygous FH (Haraki et al. 1997); however, the high HDL-cholesterol levels did not appear to protect these double heterozygotes in this population from the development of coronary heart disease.

Some familial combined hyperlipidemias in various kindreds may reflect genetic interactions among defective $L D L R$ genes, mutant $L P L$ genes, or common but unidentified alleles of other genes involved in lipid metabolism. Thus, if a defective $L D L$ receptor allele was to segregate independently but concurrently with an allele directing increased plasma triglyceride levels, the observed phenotype might resemble familial combined hyperlipidemia. The effect of interactions between mutant $L D L R$ alleles and alleles of other common lipid-related genes remains to be investigated.

The frequency with which defects in the $L D L R$ are involved in the pathogenesis of familial combined hyperlipidemia is not known at present. The observations reported here provide independent genetic evidence for the existence of a subset of patients who carry combinations of defects in several aspects of lipoprotein metabolism. These findings underscore the potential complexity among genetic factors, and probably environmental factors, that leads to the manifestation of familial combined hyperlipidemia. Our results suggest that unidentified genes are influencing the observed phenotypes. Indeed, we expect that multiple gene effects, both additive and interacting, will eventually prove to be responsible for many cases of common, inherited, mixed dyslipidemias.

Acknowledgements We thank Drs. Steven Hunt, Michael McGinty, Sawsan Ibrahim, Ed Lin, Stacey Larringa-Shum, Loni Gardner, Kyoko Shimizu, and Tomiko Matsushita for their contribution.

This work was supported by a NHLBI grant R01 HL47561 from the NIH, USA; a Grant-in-aid from the Ministry of Health and Welfare of
Japan; and a Grant-in-aid from the Ministry of Education, Science, Sports, and Culture of Japan.

\section{References}

Babirak SP, Iverius P-H, Fujimoto WY, Brunzell D (1989) Detection and characterization of the heterozygote state for lipoprotein lipase deficiency. Arteriosclerosis 9:326-334

Berger GMB, Bonnici F (1977) Familial hyperchylomicronemia in four families. S Afr Med J 51:623-628

Breslow JL (1987) Genetic regulation of apolipoproteins. Am Heart J 114:422-427

Emi M, Hegele RM, Hopkins PN, Wu LL, Plaetke R, Williams RR, Lalouel J-M (1991) Effects of three genetic loci in a pedigree with multiple lipoprotein phenotypes. Arterioscler Thromb 11:13491355

Gagne C, Brun D, Moorjani S, Lupien P-J (1977) Hyperchylomicronémie familiale: étude de l'activité lipolytique dans une famille. Union Med Can 106:333-338

Goldstein JL, Schrott HG, Hazzard WR, Bierman EL, Motulsky AG (1973) Hyperlipidemia in coronary heart disease. II. Genetic analysis of lipid levels in 176 families and delineation of a new inherited disorder, combined hyperlipidemia. J Clin Invest 52:1544-1568

Goldstein JL, Hobbs HH, Brown MS (1995) Familial hypercholesterolaemia. In: Scriver CT, Beaudet AL, Sly WS, Valle D (eds) The metabolic and molecular bases of inherited disease. McGraw-Hill, New York, pp 1981-2030

Haraki T, Inazu A, Yagi K, Kajiami K, Koizumi J, Mabuchi H (1997) Clinical characteristics of double heterozygotes with famililal hypercholesterolaemia and cholesteryl ester transfer protein deficiency. Atherosclerosis 132:229-236

Hirayama T, Yamaki E, Hara A, Tsuji M, Hashimoto K, Yamamoto M, Emi M (1998) Five familial hypercholesterolemic kindreds in Japan with novel mutation of the LDL receptor gene. J Hum Genet 43:250-254

Hopkins PN, Wu LL, Schumacher MC, Emi M, Hegele RM, Hunt SC, Lalouel J-M, Williams RR (1991) Type III dyslipoproteinemia in patients heterozygous for hypercholesterolemia and apolipoprotein E2; evidence for a gene-gene interaction. Arterioscler Thromb 11:1137-1146

Hopkins PN, Wu LL, Stephenson SH, Xin Y, Katsumata H, Nobe Y, Yamaki E, Hirayama T, Emi M, Williams RR (1999) A novel LDLR mutation, H190Y, in a Utah kindred with familial hypercholesterolemia. J Hum Genet 44:364-367

Leitersdorf E, Tobin EJ, Davignon J, Hobbs HH (1990) Common lowdensity lipoprotein receptor mutations in the French Canadian population. J Clin Invest 85:1014-1023

Leren TP, Solberg K, Rodningen OK, Ose L, Tonstad S, Berg K (1993) Evaluation of running conditions for SSCP analysis: application of SSCP for detection of point mutations in the LDL receptor gene. PCR Methods Appl 3:159-162

Mahley RW, Weisgraber KH, Farese RV (1998) Disorders of lipid metabolism. In: Wilson J, Foster DW, Kronenberg HM, Larsen PR (eds) Williams textbook of endocrinology. WB Saunders, Philadelphia, pp 1099-1153

Pimstone SN, Gagne SE, Gagne C, Lupien PJ, Gaudet D, Williams R, Kotze M, Reymer PWA, Defesche JC, Kastelein JJP, Moorjani S, Hayden MR (1995) Mutations in the gene for lipoprotein lipase. A cause for low HDL cholesterol levels in individuals heterozygous for familial hypercholesterolaemia. Arterioscler Vasc Biol 15:1704-1712

Tsukamoto K, Haruta K, Shiba T, Emi M (1998) Isolation and mapping of a polymorphic CA repeat sequence at the human interleukin 6 locus. J Hum Genet 43:71-72

Wilson DE, Edwards CQ, Chan IF (1983) Phenotypic heterogeneity in the extended pedigree of a proband with lipoprotein lipase deficiency. Metab Clin Exp 32:1107-1114

Wu LL, Warnick GR, Wu JT, Williams RR, Lalouel JM (1989) A rapid micro-scale procedure for determination of the total lipid profile. Clin Chem 35:1486-1491

Zannis VI, Breslow JL (1985) Genetic mutations affecting human lipoprotein metabolism. Adv Hum Genet 14:125-215 